\title{
Plant communities mediate the interactive effects of invasion and drought on soil microbial communities
}

\author{
Catherine Fahey $\mathbb{D}^{1} \cdot$ Akihiro Koyama $^{2} \cdot$ Pedro M. Antunes $^{3} \cdot$ Kari Dunfield $\mathbb{D}^{4} \cdot$ S. Luke Flory ${ }^{5}$
}

Received: 14 September 2019 / Revised: 15 January 2020 / Accepted: 7 February 2020 / Published online: 19 February 2020

(c) The Author(s), under exclusive licence to International Society for Microbial Ecology 2020

\begin{abstract}
Soil microbiomes could play a major role in ecosystem responses to escalating anthropogenic global change. However, we currently have a poor understanding of how soil microbes will respond to interacting global change factors and if responses will be mediated by changes in plant community structure. We used a field experiment to assess changes in soil fungal and bacterial communities in response to plant invasion, experimental drought, and their combination. In addition, we evaluated the relative importance of direct versus indirect pathways of invasion and drought through changes in associated plant communities with structural equation models. We found that fungal communities were interactively structured by invasion and drought, where fungal richness was lowest with invasion under ambient conditions but highest with invasion under drought conditions. Bacterial richness was lower under drought but unaffected by invasion. Changes in the plant community, including lower plant richness and higher root biomass, moderated the direct effects of invasion on microbial richness. Fungal and bacterial functional groups, including pathogens, mutualists, and nitrogen metabolizers, were also influenced by plant community changes. In sum, plant communities mediated the effects of interacting global change drivers on soil microbial community structure, with significant potential consequences for community dynamics and ecosystem functions.
\end{abstract}

\section{Introduction}

Soil microbiomes provide essential ecosystem services that may be altered by interacting global change factors [1]. Changes in microbial community composition in response to multiple global change factors, such as elevated $\mathrm{CO}_{2}$

Supplementary information The online version of this article (https:// doi.org/10.1038/s41396-020-0614-6) contains supplementary material, which is available to authorized users.

Catherine Fahey

Catherine.fahey@algomau.ca

1 School of Natural Resources and Environment, University of Florida, Gainesville, FL, USA

2 Department of Forestry, Michigan State University, East Lansing, MI, USA

3 Biology Department, Algoma University, Sault Ste. Marie, Ontario, Canada

4 School of Environmental Science, University of Guelph, Guelph, ON, Canada

5 Agronomy Department, University of Florida, Gainesville, FL, USA concentration, temperature, and precipitation may be nonadditive [2,3], there may be no change [4], or fungi and bacteria may respond differently [5]. These responses are even more uncertain when considering interactions between biotic (e.g., plant invasion) and abiotic (e.g., precipitation) global change factors [6]. Furthermore, microbial communities may be changed directly by global change factors, such as invasion or drought [7], or indirectly through shifts in plant community structure or function in response to altered conditions [8-11]. Alteration of plant communities by multiple global change factors may have indirect consequences for soil microbial communities that are difficult to predict.

Plant communities can play a major role in shaping soil microbial communities via root structure and exudation as well as litter inputs and microclimate effects [9, 12-16]. Non-native invasive plants may change microbial communities directly (e.g., through production of allelochemicals in the rhizosphere that inhibit mutualists) [17]. However, invasive plants also can have impacts on plant communities (e.g., reduced plant diversity) that could indirectly alter microbial communities through, for example, changes in root exudate profiles or availability of host plants $[12,16,18]$. The indirect effects of invasion on microbial 
communities could act in the same direction as the direct effects of the invader or they could counteract the direct effects of the invader.

Greater frequency and severity of regional droughts is likely to produce major changes in soil microbial communities, ecosystem functions, and plant-microbe interactions $[19,20]$. Drought can cause rapid declines in microbial activity as well as shifts in the abundance of different microbial taxa, which may influence the rates of decomposition and nutrient cycling [2, 21-23]. Invasive plants could mediate drought effects either through physiological (e.g., water-use) or biophysical (e.g., shading, infiltration) effects [6, 24, 25]. Conversely, drought could modify the effects of invasive plants on soil microbes via changes in invader abundance or altered invader physiology (e.g., root exudates, litter inputs) [26]. Furthermore, changes in abundance of certain fungal and bacterial groups can mediate plant responses to drought [27, 28]. Altogether, plant-microbe interactions are likely to be modified by drought and interactions with plant invaders; however, our ability to predict these changes is limited.

Longleaf pine (Pinus palustris) forests with highly diverse understory plant communities historically covered $\sim 30$ million hectares of the southeastern US, but only $3 \%$ of their original extent remains [29]. Invasive species such as Imperata cylindrica (cogongrass), a $\mathrm{C}_{4}$ grass from Asia [30], can greatly reduce plant diversity of longleaf pine forests and threaten rare native plant species [31, 32]. Climate models suggest that I. cylindrica invasion will accelerate as the southeastern US experiences greater frequency and duration of droughts over the next several decades [20,33]. Therefore, to improve ecosystem management under global change, it is critical to understand the individual and combined impacts of invasion and drought on soil microbial communities.

Modern sequencing technologies allow for assessments of microbial community changes at greater taxonomic resolution and organization of microbes into functional groups, which can improve our understanding of the ecological interactions occurring belowground [34-36]. Consequently, it is possible to evaluate microbial responses to global change, and potential effects on ecosystem functions [37]. Microbes with different functional roles are likely to show divergent responses to interacting global change factors. For example, the invader I. cylindrica is thought to produce allelopathic chemicals that reduce ectomycorrhizal colonization of pines [38], but I. cylindrica associates with arbuscular mycorrhizal (AM) fungal mutualists, suggesting that AM fungal abundance may increase with invasion [39]. Thus, an improved understanding of the responses of microbial taxonomic and functional groups to invasion and drought is essential for moving towards a mechanistic understanding of plant-microbe-ecosystem interactions.
To evaluate the potential interactive effects of plant invasion and drought on soil microbial communities, we sampled soil from a long-term field experiment to investigate the soil microbiome. Our aims were: (1) to determine how plant invasion and drought independently and interactively affect fungal and bacterial community structure and the relative abundance of taxonomic and functional groups, and (2) to parse out the importance of direct effects of invasion and drought versus the indirect effects through changes in plant community structure. We hypothesized that there would be direct negative effects of both invasion and drought on microbial richness, as well as indirect effects of the global change drivers through changes in the associated plant communities. Specifically, we expected that reductions in plant diversity, pine abundance, and root biomass would reduce microbial richness. Altogether, we aimed to provide an improved mechanistic understanding of soil microbial responses to multiple interacting global change drivers.

\section{Methods}

\section{Experimental design}

The Bivens Arm Research Site (BARS) was established at the University of Florida in Gainesville, Florida, USA $\left(29^{\circ} 37^{\prime} 42^{\prime \prime} \mathrm{N}, 82^{\circ} 21^{\prime} 14.4^{\prime \prime} \mathrm{W}\right)$. Mean annual temperature and precipitation are $20.5^{\circ} \mathrm{C}$ and $1300 \mathrm{~mm}$, respectively. Soils are primarily Portsmouth sandy loam composed of Blichton sand (25\%; 2-5\% slope) and Bivans sand (75\%; 5-8\% slope; Natural Resources Conservation Service, Web Soil Survey) with soil textures ranging from loamy sand to sandy loam. The study area of $\sim 30 \mathrm{~m} \times 60 \mathrm{~m}$ was mowed and tilled to prepare the site. Soils across the plots were similar in particle size distribution and bulk density (Tables S1, S2). In May 2012, plant communities were established in forty $4 \mathrm{~m} \times 4 \mathrm{~m}$ plots with 36 native perennial grass and forb seedlings (12 spp. $\times 3$ individuals; The Natives Inc., Davenport, FL) and 20 longleaf pine seedlings per plot (Florida Forest Service, Chiefland, FL). Many additional species colonized the plots from the soil seedbank and the surrounding area [32].

In spring 2013, a blocked factorial combination of $I$. cylindrica "invasion" and precipitation reduction (hereafter referred to as "drought") was applied (ten replicates per treatment combination). Nine I. cylindrica ramets were added into each invaded plot. The drought treatment consisted of rainout shelters with $89 \%$ cover of polycarbonate roofing (TUFTEX PolyCarb, Fredericksburg, VA) and gutters connected to pipes to move the water off site. Around each drought plot, belowground plastic barriers were inserted to $1 \mathrm{~m}$ depth to inhibit subsurface flow of water, and aluminum flashing extended $10 \mathrm{~cm}$ above the 
soil surface to reduce overland flow. Structures were constructed over no-drought control plots (hereafter "ambient") with $22 \%$ white shade cloth to mimic shading by the rainout shelters [24]. As extreme climate events are expected to increase in the Southeast US, we aimed to create a severe drought scenario [20, 40]. Based on local historical data, a 100 -year drought in the region would be a $66 \%$ reduction in precipitation compared with the long-term average. It has been shown that for high levels of rain exclusion, the precipitation removed with rainout shelters tends to be less than the percent cover of roofing [41]. Furthermore, heavy precipitation events and strong winds are common in Florida, so we expected the precipitation reduction to be considerably less than the roofing cover. Volumetric soil moisture was on average 30-50\% lower in the drought plots compared with the ambient precipitation plots over the first 3 years of the experiment [24]. The drought treatment remained in place from March 2013 through the time of soil sampling in June 2016.

Soil samples were collected in mid-June 2016 from the experimental plots using a $5 \mathrm{~cm}$ diameter hammer corer (AMS Inc., American Falls, ID). Surface plant litter was removed, and three cores per plot were extracted to a depth of $15 \mathrm{~cm}$. The $5-15 \mathrm{~cm}$ fraction of the three cores per plot was composited and homogenized through a $2 \mathrm{~mm}$ sieve. Separate sieves were used for each treatment and sieves were washed in between samples to reduce the chance of cross-contamination. A $5 \mathrm{~g}$ subsample of fresh soil was dried at $105^{\circ} \mathrm{C}$ for $72 \mathrm{~h}$ and weighed to calculate gravimetric soil moisture. All roots were hand sorted from the soil, washed, dried at $60^{\circ} \mathrm{C}$ for $48 \mathrm{~h}$, and weighed. Soils were then frozen at $-10^{\circ} \mathrm{C}$ for transport and then at $-80^{\circ} \mathrm{C}$ until DNA extraction.

\section{DNA extraction, PCR, and Illumina sequencing}

Genomic DNA was extracted from each soil sample $(0.25 \mathrm{~g})$ using MoBio PowerSoil DNA extraction kit (MOBIO Laboratories, Inc., Carlsbad, CA, USA). The fungal ITS2 and bacterial 16S rRNA genes were amplified for each sample using primer sets of 5.8S-FUN/ITS4-FUN [42] and F515/R806 [43], respectively. We used the 5.8S-FUN/ ITS4-FUN primers because they were designed to capture the broadest array of fungi and have been shown to work well for specific groups of fungi such as the Glomeromycota [44]. The primers were modified for the Illumina platform by fusing CS1 and CS2 linker primers for forward and reverse primers, respectively.

Polymerase chain reactions were conducted with $50 \mu \mathrm{L}$ assays. For the fungal ITS2 amplification, $25 \mu \mathrm{L}$ of $\mathrm{GoTaq}^{\circledR}$ Colorless Master Mix, $5 \mu \mathrm{L}$ of BSA $\left(5 \mathrm{ng} \mu \mathrm{L}^{-1}\right), 0.8 \mu \mathrm{L}$ of each primer $(10 \mu \mathrm{M}), 8 \mu \mathrm{L}$ of PCR-grade water, and $10.4 \mu \mathrm{L}$ of a genomic DNA template $\left(5 \mathrm{ng} \mathrm{L}^{-1}\right)$ were mixed in a
200- $\mu \mathrm{L}$ PCR tube for each sample. The following thermal profile was used for the fungal PCR: an initial denaturation and enzyme activation step of $96^{\circ} \mathrm{C}$ for $2 \mathrm{~min}$, followed by 30 cycles of $94{ }^{\circ} \mathrm{C}$ for $30 \mathrm{~s}, 58^{\circ} \mathrm{C}$ for $40 \mathrm{~s}$, and $72^{\circ} \mathrm{C}$ for $120 \mathrm{~s}$, with a final extension of $72^{\circ} \mathrm{C}$ for $10 \mathrm{~min}$. For the $16 \mathrm{~S}$ amplification, $25 \mu \mathrm{L}$ of GoTaq $^{\circledR}$ Colorless Master Mix (Promega, Madison, Wisconsin, USA), $5 \mu \mathrm{L}$ of BSA $\left(5 \mathrm{ng}_{\mu} \mathrm{L}^{-1}\right), 1 \mu \mathrm{L}$ of each primer $(10 \mu \mathrm{M}), 15 \mu \mathrm{L}$ of PCR-grade water, and $3 \mu \mathrm{L}$ of a genomic DNA template $\left(5 \mathrm{ng} \mu \mathrm{L}^{-1}\right)$ were mixed in a $200-\mu \mathrm{L}$ PCR tube for each sample. The following thermal profile was used for bacterial PCR: an initial denaturation and enzyme activation step of $94{ }^{\circ} \mathrm{C}$ for $3 \mathrm{~min}$, followed by 30 cycles of $94{ }^{\circ} \mathrm{C}$ for $45 \mathrm{~s}$, $50{ }^{\circ} \mathrm{C}$ for $60 \mathrm{~s}$, and $72{ }^{\circ} \mathrm{C}$ for $90 \mathrm{~s}$, with a final extension of $72{ }^{\circ} \mathrm{C}$ for $10 \mathrm{~min}$. Qualities of PCR products were evaluated by agarose gel electrophoresis. Additional rounds of PCR were performed to fuse CS1/CS2 linker primers to the indices and adapters (an initial denaturation and enzyme activation at $95^{\circ} \mathrm{C}$ for $10 \mathrm{~min}$, followed by 15 cycles at $95^{\circ} \mathrm{C}$ for $15 \mathrm{~s}, 60^{\circ} \mathrm{C}$ for $30 \mathrm{~s}$, and $72^{\circ} \mathrm{C}$ for $60 \mathrm{~s}$ with a final extension at $72{ }^{\circ} \mathrm{C}$ for $10 \mathrm{~min}$ ) before Illumina MiSeq PE250 sequencing at Génome Québec (Montréal, Québec, Canada). The Illumina sequences were deposited at NCBI (accession number SAMN09623609 to SAMN09623688).

\section{Sequence data processing}

QIIME 1.9.0 toolkit [45] was used to process the Illumina sequences using the standard protocol for bacteria, and a protocol developed for fungal sequences amplified by the 5.8-FUN/ITS4-FUN primers [42]. Chimeric 16S and ITS2 sequences were identified using reference-based (May 2013 version of Greengenes database, [46]) and abundancebased methods, respectively, via USEARCH [47], and removed for downstream analyses. Operational taxonomic units (OTUs) were determined at the $\geq 97 \%$ similarity level of the nucleotide sequences [48] using the open-reference OTU picking option. ITS2 sequences were first extracted from representative OTU sequences via ITSx [49]. Taxonomy was assigned to each OTU via BLAST [50] against the UNITE [51] and Greengenes [46] databases for ITS2 and $16 \mathrm{~S}$ sequences, respectively.

For the fungal ITS2 sequences, non-fungal sequences, which accounted for $38.6 \%$ of OTUs and $34.6 \%$ of the total sequences, were removed for downstream analyses. We defined "non-fungal sequences" as those that could not be categorized as fungi at the kingdom level against the UNITE database. Because 5.8S-FUN/ITS4-FUN can amplify non-fungal sequences, we used only sequences that we could confidently identify as fungi [52]. The fungal data were rarefied at 13,300 sequences per sample, resulting in a data set with a total of 3562 OTUs. Numbers of identified fungal phyla, classes, orders, families, and genera in the 
rarefied fungal data set were $10,32,91,229$, and 458 , respectively. FUNGuild was employed to categorize the OTUs into trophic modes and guilds, including plant pathogens, mutualists, and saprotrophs [35]. We used only taxa where the confidence ranking for the guild assignment was rated either "probable" or "highly probable".

For the 16S sequences, de novo sequences, which accounted for $90.1 \%$ of OTUs but only $18.6 \%$ of the total sequences, were removed for downstream analyses. After non-bacterial sequences and singletons were removed, remaining 16S sequences were aligned using PyNAST [45] to build a phylogenetic tree using FastTree [53]. The bacterial sequences were rarefied at 71,166 sequences per sample, resulting in a data set with a total of 8534 OTUs. Numbers of identified bacterial phyla, classes, orders, families, and genera in the rarefied fungal data set were 36, 111, 173, 209, and 284, respectively. The FAPROTAX database was used to extrapolate bacterial taxa into putative functional roles [54]. Further studies would be required to assess gene expression for these putative functions.

\section{Statistical analyses}

Statistical analyses were conducted in R 3.4.1 [55]. Mixedeffect models using the nlme package were conducted with the invasion and drought treatments and their interaction as fixed effects and block as a random effect [56]. OTU richness, Shannon diversity index, Pielou's evenness, and Chaol index of fungi and bacteria were used as dependent variables [57]. Plant, fungal, and bacterial community composition were assessed using ordination by nonmetric multidimensional scaling (NMDS) calculated with the "metaMDS" function of the vegan package [58]. Plant community data were taken from an associated publication [32]. The bacterial community was assessed with the weighted and unweighted UniFrac distance matrix, and the fungal community with the Bray-Curtis dissimilarity matrix. We tested for differences in community composition with invasion, drought, and their interactions with permutational multivariate analysis of variance (PERMANOVA) with 999 permutations and permutations constrained within each block using "adonis" from the vegan package [58]. We also tested for homogeneity of group dispersions with the multivariate analog of Levene's test using the "betadisper" function in the vegan package [59].

The effect of invasion and drought on relative abundance of fungal and bacterial taxa and functional groups that occurred in at least $25 \%$ of the sample units was tested using the analysis of composition of microbiomes (ANCOM) with a cut off of $W>0.75$ [60].

\section{Structural equation models}

Piecewise structural equation models (SEMs) were used to compare the direct and indirect effects of the treatments using the piecewiseSEM package [61]. The specific hypothesized interactions included in the models are outlined in Fig. 1. For the indirect effects via changes in the plant

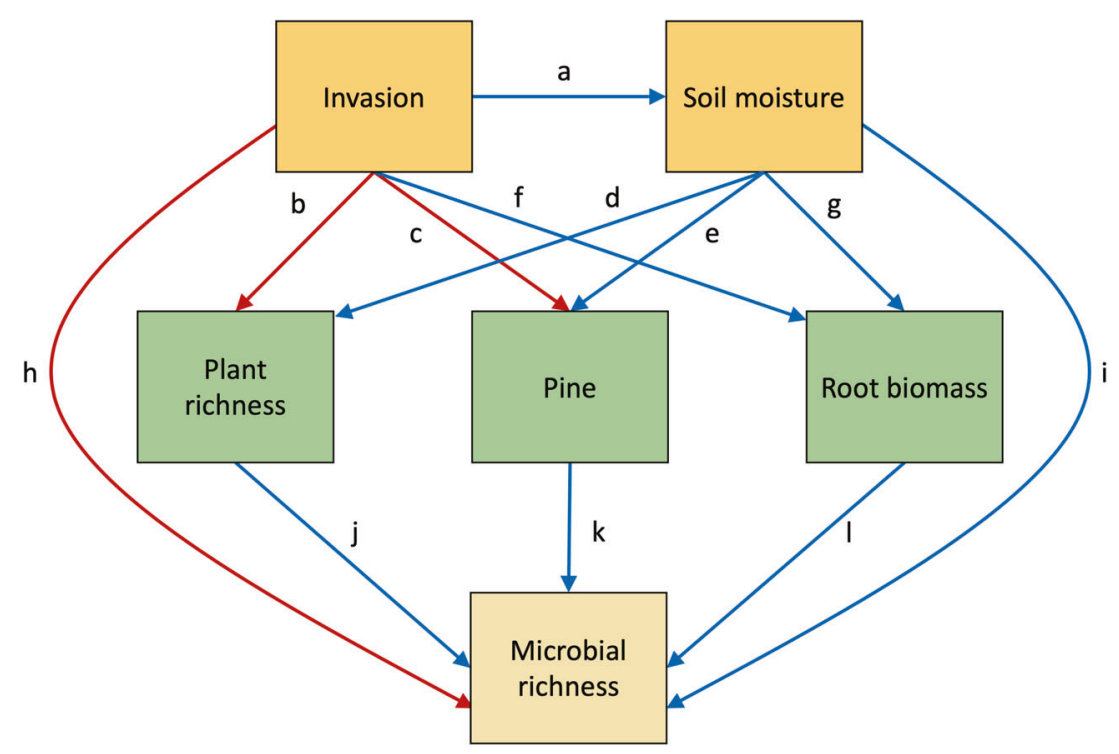

Fig. 1 Hypothesized direct and indirect effects of invasion and soil moisture on soil microbial richness, with indirect effects through changes in the plant community (green boxes). Blue arrows indicate hypothesized positive effects and red arrows indicate negative effects. In previous studies from this experiment, we showed that invasion resulted in higher soil moisture, especially under drought conditions (a), and that invasion and drought both reduced plant species richness and longleaf pine abundance $(\mathbf{b}-\mathbf{e})$. We predicted that invasion would promote but drought would reduce root biomass (f, $\mathbf{g})$; invasion and drought would directly reduce microbial diversity $(\mathbf{h}, \mathbf{i})$; and greater plant diversity, pine abundance, and root biomass would increase microbial diversity $(\mathbf{j}-\mathbf{l})$. 
Fig. 2 Environmental and plant communitiy variables used in the structural equation models. (a) Percent soil moisture, (b) plant species richness, (c) percent cover of longleaf pine, (d) total root biomass in the $5-15 \mathrm{~cm}$ depth soil fraction, as affected by $I$. cylindrica invasion and drought treatment with ambient precipitation shown in white and drought treatment in back (mean $\pm \mathrm{SE}, N=10)$.
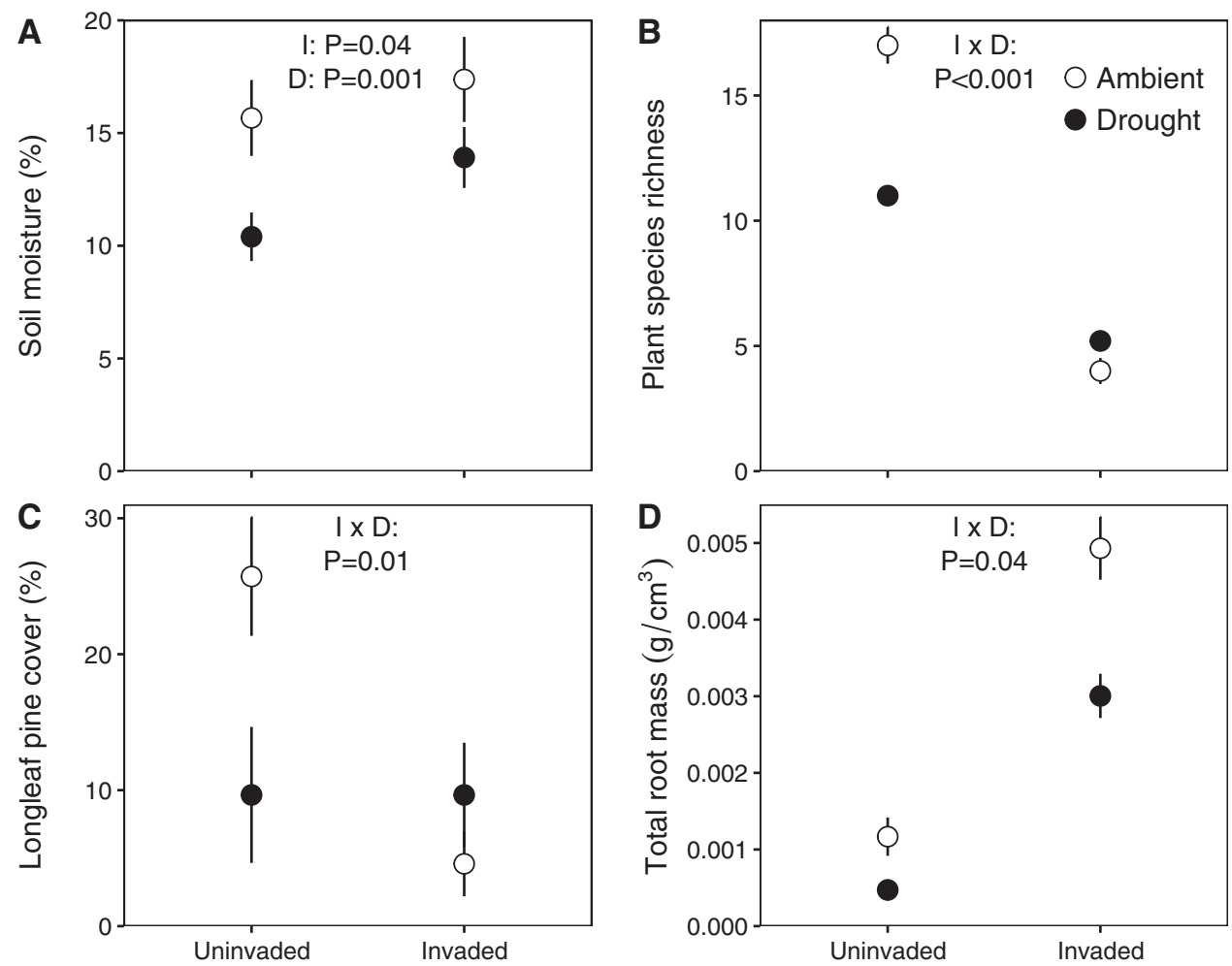

community, plant richness provided an estimate of the complexity of the plant community; the cover of longleaf pine represented a foundation species and a functionally distinct species in the community; and root biomass estimated the belowground productivity of the system. Invasion was specified as a categorical exogenous variable, and gravimetric soil moisture, plant species richness, cover of longleaf pine, and root biomass as endogenous variables. Paths were included from invasion and soil moisture to all other endogenous variables. A path from invasion to soil moisture was included because previous research showed that $I$. cylindrica increased soil moisture, particularly under drought conditions [24]. Paths were included from plant species richness, root biomass, and pine abundance to the microbial community variables. Microbial community variables were fungal and bacterial richness and functional groups. These variables were used in linear mixed effects models with block as a random effect in the piecewise SEM. The initial test of $d$-separation (Fisher's $\mathrm{C}=11.6, P=0.07$ ) suggested that longleaf pine cover and plant species richness were not independent $(P=0.005)$. This correlation was likely due to similar responses of longleaf pine and herbaceous plants to the treatments $[32,62]$, thus, covariance between these variables was included in the final model. The final test of $d$-separation (Fisher's $C=0.91, P=0.92$ ) showed a good model fit. A stepwise removal of the least significant paths from the models was conducted until either the AIC did not decrease with removal of the next parameter or there were no remaining parameters with $P>0.1$.

\section{Results}

At the time of sampling, soil moisture was $26 \%$ lower in drought plots than ambient plots, and $20 \%$ higher in invaded plots than uninvaded plots (D: $F_{1,27}=12.6, P=0.001$; I: $F_{1,27}=4.5, P=0.04$; Fig. 2 a). Plant species richness was $76 \%$ lower under invasion alone, $35 \%$ lower under drought alone, and $69 \%$ lower in invaded drought plots than uninvaded ambient plots $\left(\mathrm{I} \times \mathrm{D}: F_{1,27}=79.2, \quad P<0.001\right.$; Fig. 2b). Plant community composition was strongly affected by invasion (I: Pseudo- $\mathrm{F}_{1,39}=12.3, P<0.01$ ) and marginally affected by the interaction of invasion and drought ( $\mathrm{I} \times \mathrm{D}$ : Pseudo- $\mathrm{F}_{1,39}=2.1, \quad P=0.06$; Fig. 4a). Longleaf pine cover was $82 \%$ lower under invasion alone and $62 \%$ lower under drought both with and without the invader compared with the uninvaded ambient plots $(\mathrm{I} \times \mathrm{D}$ : $F_{1,27}=7.6, P=0.01$; Fig. 2 c). Total root biomass was over four times higher with invasion alone, $40 \%$ lower with drought alone, and 2.6 times higher in invaded drought plots than in uninvaded ambient plots $\left(\mathrm{I} \times \mathrm{D}: F_{1,27}=4.8\right.$, $P=0.04$; Fig. 2d; Table S3).

\section{Microbial diversity and community composition}

Fungal OTU richness and Chao 1 index were interactively affected by invasion and drought. Under ambient conditions invasion reduced richness by 56 OTUs but under drought conditions invasion promoted richness by 48 OTUs $(\mathrm{I} \times \mathrm{D}$ : $P=0.02$; Fig. 3a). Fungal diversity and evenness showed 
Fig. 3 Effects of invasion and drought treatments on microbial richness. Richness of (a) fungal and (b) bacterial OTUs with ambient precipitation shown in white and drought treatment in black (mean $\pm \mathrm{SE} ; N=10$ )
A

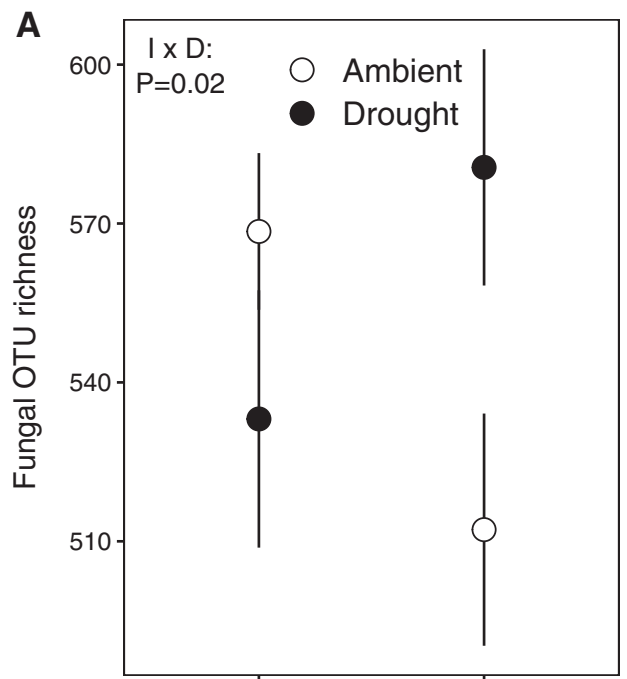

Uninvaded

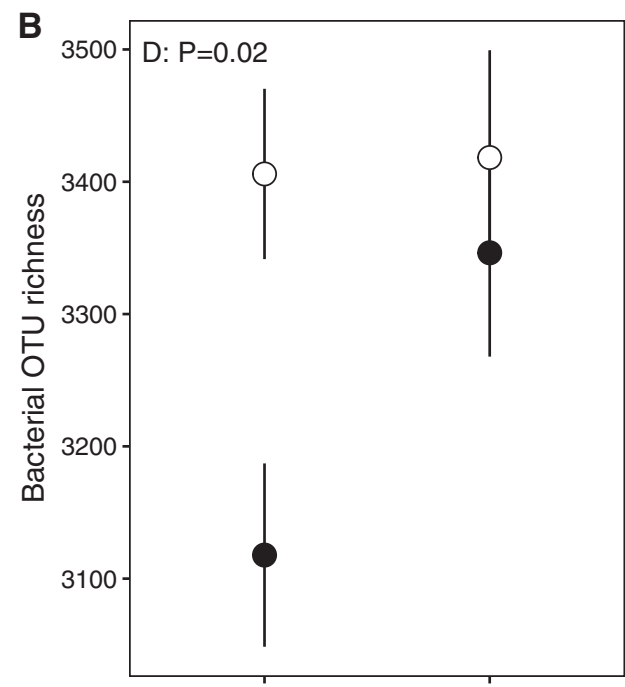

Uninvaded

Invaded

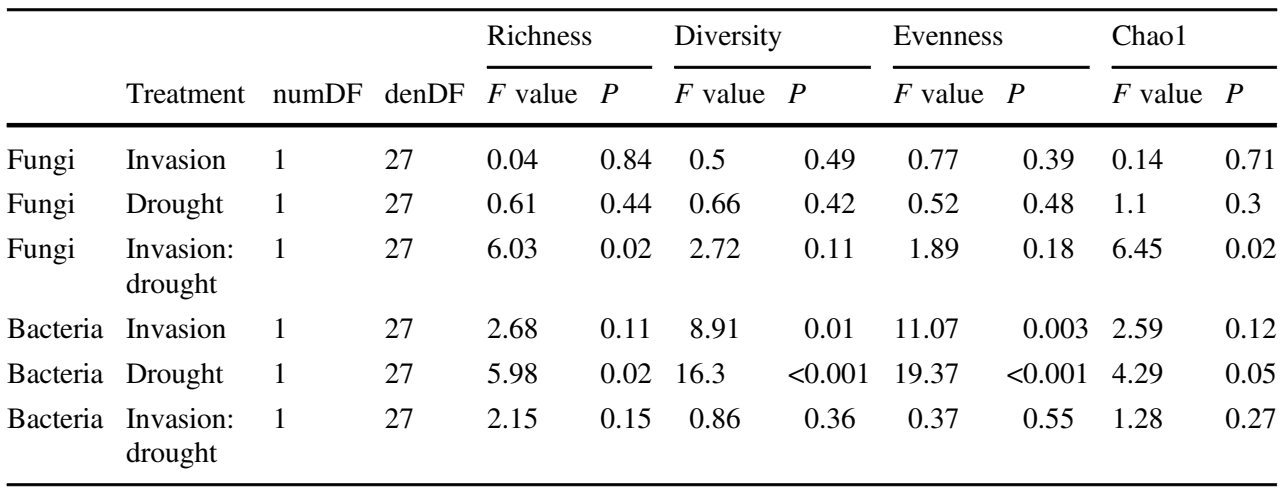

Table 1 Results of mixed effects models of invasion and drought treatment effects on fungal and bacterial richness, Shannon diversity index, Pielou's evenness, and Chao 1 index. the same trend as richness $(\mathrm{I} \times \mathrm{D}: P=0.11, P=0.18$, respectively; Fig. S1, Table 1). Invasion resulted in greater Shannon diversity index and evenness of soil bacteria with a similar trend for richness and Chao 1 index ( $\mathrm{I}$ : $\mathrm{P}=0.01$, 0.003 , 0.11, 0.12, respectively; Table 1; Fig. 3b). The effects of the drought treatment were evident in lower bacterial Shannon diversity index, evenness, OTU richness, and Chao 1 index (D: $P=0.001,0.001,0.02,0.048$, respectively, Fig. S2). On average, drought plots had 180 fewer bacterial OTUs than ambient precipitation plots.

Invasion and drought interactively affected fungal community composition where uninvaded ambient plots and invaded drought plots had similar composition, while invaded ambient plots and uninvaded drought plots were similar in composition $(\mathrm{I} \times \mathrm{D}: \quad P=0.001$; Fig. $4 \mathrm{~b}$; Table S4). For bacteria, drought was the strongest driver of community composition with a weak interaction between invasion and drought (weighted UniFrac: $\mathrm{D}: P=0.002, \mathrm{I} \times$ D: $P=0.26$; unweighted UniFrac: $\mathrm{D}: P=0.001, \mathrm{I} \times \mathrm{D}$ : $P=0.06$; Fig. 4c, d; Table S4). There were significant differences in dispersion between treatments for the plant community $(P=0.003)$ [32], but neither fungal nor bacterial communities showed differences in treatment group dispersion (Fungi: $P=0.96$; Bacteria unweighted UniFrac: $P=0.37$; Bacteria weighted UniFrac: $P=0.59$ ).

\section{Fungal groups}

No fungal phyla or classes were differentially abundant under the treatments (Figs. S3 and S4). All of the fungal orders and families that responded to the treatments were rare (i.e., $<1 \%$ relative abundance), except for Atheliales/ Atheliaceae. Six of 62 fungal orders that occurred in at least $25 \%$ of the samples were affected by the treatments (Fig. S5). Sebacinales was more abundant with invasion (I: $W=0.89)$. Glomerales and Umbelopsidales were less abundant under drought (D: $W=0.79,0.77$, respectively). Phacidiales, Atheliales, and Venturiales were all less abundant in invaded ambient plots and uninvaded drought plots than the other treatments $(\mathrm{I} \times \mathrm{D}: W=0.95,0.94,0.79$, respectively). Five fungal families out of 157 were affected by the treatments (Fig. S6). Serendipitaceae was more abundant in invaded plots (I: $W=0.94$ ) and Umbelopsidaceae and Glomeraceae were less abundant under drought 
Fig. 4 Nonmetric

multidimensional scaling ordinations of community dissimilarities among invasion and drought treatments. (a) Bray-Curtis dissimilarity of plant community composition (stress $=0.164),(\mathbf{b})$ Bray-Curtis dissimilarity of the fungal community (stress $=0.199)$, $(\mathbf{c})$ unweighted UniFrac distance of the bacterial community (considers presence-absence; stress $=0.152),(\mathbf{d})$ weighted UniFrac distance of the bacterial community (considers relative abundance; stress $=0.169$ ) Larger points with error bars indicate the mean \pm SE of the 10 plots per treatment and smaller background points show NMDS values for each plot. Light blue points indicate uninvaded plots with ambient precipitation, dark blue points indicate invaded plots with ambient precipitation, orange points indicate uninvaded drought plots, and red points indicate invaded drought plots.
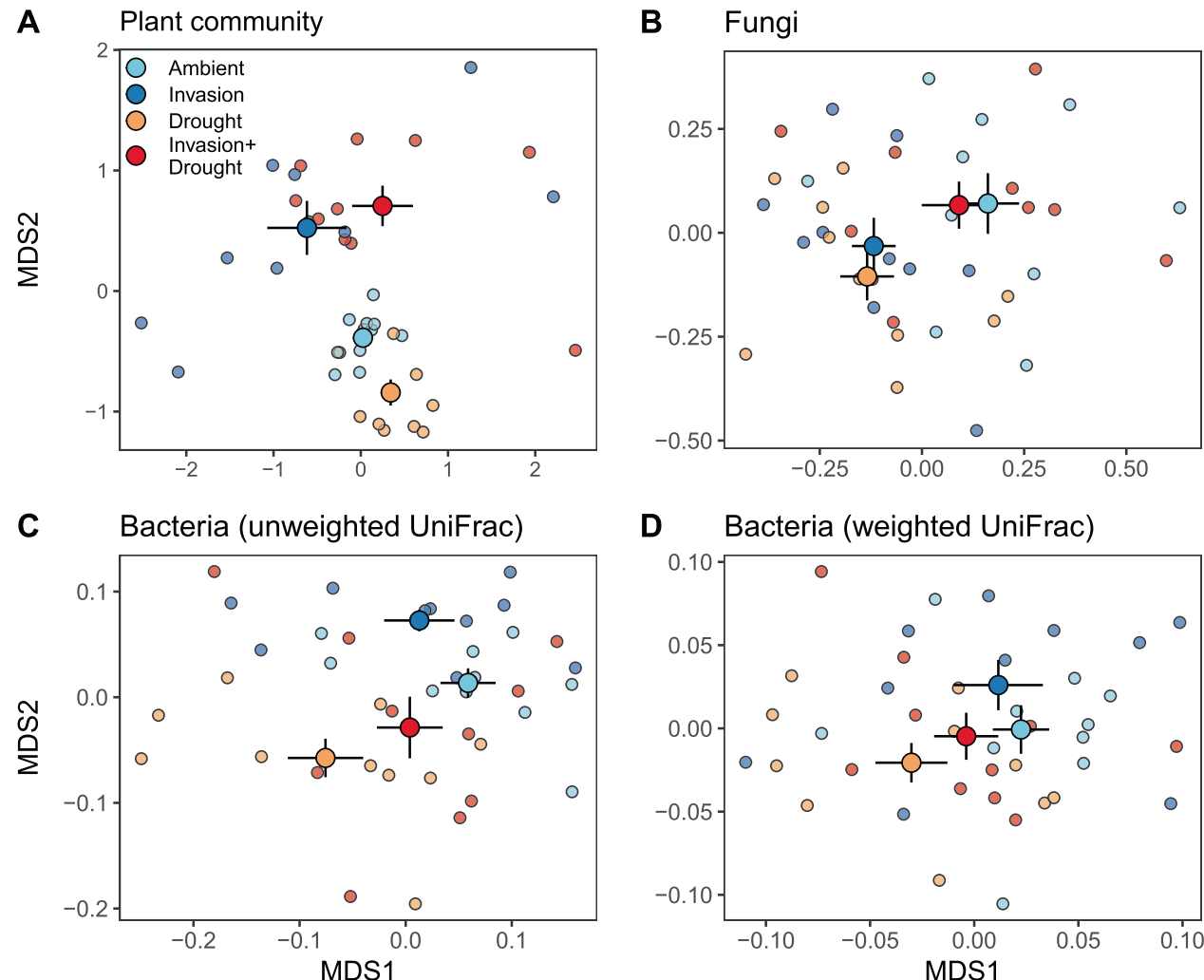

(D: $W=0.87$ ). Phacidiaceae and Atheliaceae were less abundant with invasion and drought individually compared with uninvaded ambient plots and invaded drought plots $(\mathrm{I} \times \mathrm{D}: W=0.97,0.96$, respectively).

In the fungal dataset, $69 \%$ of OTUs were identified as having known guilds based on the FUNGuild database and $81 \%$ of those OTUs had a confidence ranking of probable or highly probably. There were no significant effects of the treatments on fungal guilds; however, there was a marginal effect of drought on the guild "Endophyte, Undefined Saprotroph, Wood Saprotroph" and a marginal interaction between invasion and drought on the guild "Animal Pathogen, Fungal Parasite, Undefined Saprotroph" ( $W=0.74$; Fig. S7).

\section{Bacterial groups}

Only relatively rare bacterial taxa (i.e., $<1 \%$ relative abundance) were affected by the treatments, including $4 / 32$ phyla (Fig. S8). Fibrobacteres were over seven times and Spirochaetes over three times more abundant in invaded plots (I: $W=0.88,0.81$, respectively). Bacteria in candidate division TM7 were 2.4 times more abundant under drought ( $W=0.90)$, while FCPU426 were $73 \%$ less abundant under drought than ambient conditions (D: $W=0.77)$. Ten out of 91 bacterial classes were affected by the treatments (Fig. S9). Fibrobacteria were 7.5 and Spirochaetia were 4.3 times more abundant with invasion (I: $W=0.92,0.85$ ). Holophagae, Pla4, OM190, Chlamydiia, Cytophagia, and PRR-12 were less abundant under drought (D: $W=0.96$, $0.91,0.89,0.80,0.79,0.79$, respectively), while TM7-1 and TM7-3 were more abundant under drought (D: $W=0.96$, 0.89 , respectively). Four of 136 bacterial orders and seven of 152 families were affected by drought, two orders and one family by invasion, and one order and one family by the interaction of invasion and drought (Figs. S10 and S11, and Table S5).

In the bacterial dataset, $20 \%$ of OTUs were identified as having at least one known putative function in the FAPROTAX database. Most bacterial groups had several assigned functions, so we refer to the functional groups by number (based on rank of relative abundance) and a single key function. A complete list of bacterial functional groups is given in Table S6. Five out of 48 bacterial functional groups were affected by drought, where FG2-denitrifiers and FG13-human pathogens were more abundant under drought while, FG6-intracellular parasites, FG10-cyanobacteria, and FG16-fermenters were less abundant with drought $(\mathrm{W}=$ $0.96,0.81,0.77$, respectively). FG8-nitrate reduction was marginally less abundant under drought $(W=0.72)$. No functional groups responded to the invasion treatment. FG9ureolysis responded interactively to invasion and drought where abundance was lower with invasion and drought independently but higher with invasion and drought together 
A

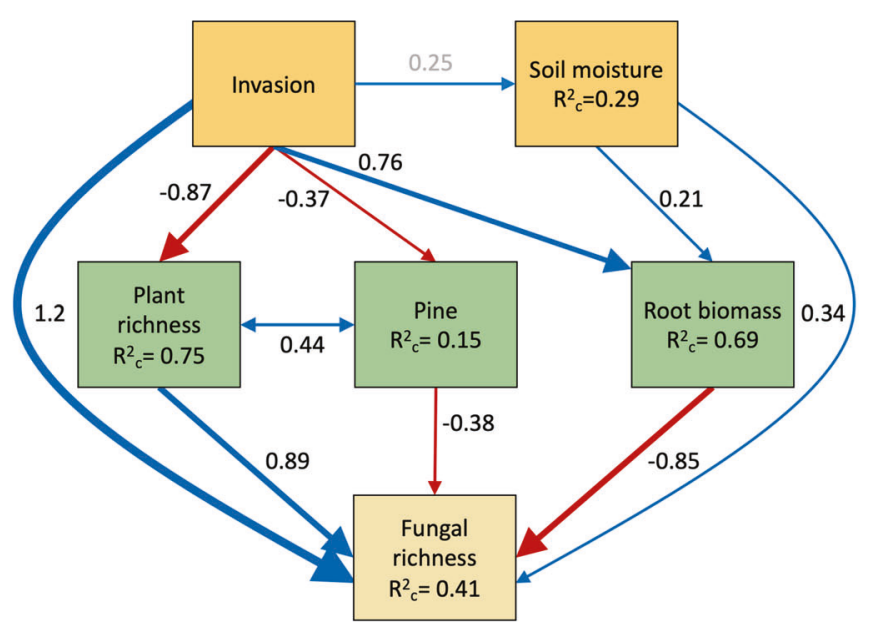

Fig. 5 Path diagrams showing the relationships between invasion and drought treatments, plant communties, and microbial richness. (a) Fungal and (b) bacterial richness where blue arrows indicate positive relationships and red arrows indicate negative relationships. Standardized path coefficients are shown next to the arrows and arrow size is scaled to the strength of the coefficients. Solid arrows and black coefficients

$(W=0.79$; Fig. S12). Table S5 provides the complete ANCOM results.

\section{Drivers of microbial community structure}

The structural equation models explained $41 \%$ and $27 \%$ of the variability in fungal and bacterial richness, respectively. Invasion had a negative effect on plant richness (standardized coefficient $=-0.87, P<0.001)$ and pine abundance (std. coefficient $=-0.37, P=0.02$ ) but a positive effect on root biomass (std. coefficient $=0.76, P<0.001$; Fig. 5a). Soil moisture had a positive effect on root biomass (std. coefficient $=0.21, P=0.03$ )

Invasion had a direct positive effect on fungal richness (std. coefficient $=1.2, P<0.001$ ) and a positive indirect effect through pine cover (std. coefficient $=0.14$ ). However, invasion also had negative indirect effects through plant richness (std. coefficient $=-0.77$ ) and root biomass (std. coefficient $=-0.65$; Fig. 5a), resulting in a small negative overall effect of invasion (std. coefficient $=$ $-0.07)$. Soil moisture had a direct positive effect on fungal richness (std. coefficient $=0.34, P<0.001$ ) but an indirect negative effect through root biomass (std. coefficient $=$ -0.18 ), resulting in a positive overall effect of soil moisture (std. coefficient $=0.17$ ).

Invasion had a direct positive effect on bacterial richness (std. coefficient $=0.80, P=0.04$ ), but there was also an indirect negative effect of invasion on bacterial richness through plant species richness (std. coefficient $=-0.80$ ), resulting in a more moderate overall positive effect of invasion on bacterial richness ( $\mathrm{std}$. coefficient $=0.24$ ).

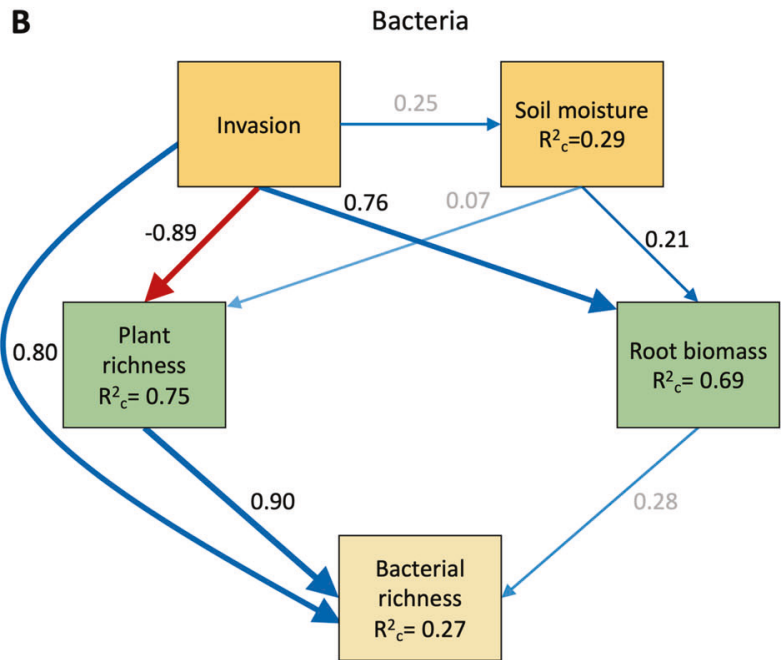

indicate a significant relationship $(P<0.05)$ while faded arrows and gray coefficients indicate a non-significant relationship $(P>0.05)$ and the level of transparency of the arrows corresponds to the $P$ value. The conditional $R^{2}$ (based on the variance of both the fixed and random effects) for the component mixed effects models are shown in the boxes for the response variables.

There was no direct effect of soil moisture on bacterial richness, and the indirect effects of soil moisture on bacterial richness were not significant (std. coefficient $=0.06$; Fig. 5b).

The structural equation model for fungal guilds explained $48 \%$ of the variability in plant pathogen relative abundance, $30 \%$ of AM fungal relative abundance, $63 \%$ of ectomycorrhizal fungal relative abundance, and $58 \%$ of saprotroph relative abundance. Plant pathogen relative abundance was directly positively affected by higher soil moisture (std. coefficient $=0.38, P<0.01$ ) but negatively affected by root biomass (std. coefficient $=-0.59$ ), resulting in indirect negative effect of soil moisture (std. coefficient $=-0.12$ ). Invasion had opposing indirect effects on the abundance of plant pathogens through abundance of pines and root biomass (std. coefficients $=0.22,-0.45$ ), creating an overall negative effect of invasion on plant pathogens (std. coefficient $=-0.23$; Fig. 6a). There was no direct effect of invasion or soil moisture on AM fungi (Fig. 6b). Their abundance was greater with higher root biomass, which was promoted by invasion and soil moisture, creating positive indirect paths from invasion and soil moisture to AM fungal abundance (std. coefficients $=0.47$, 0.13). Invasion also had an indirect negative effect on AM fungi through plant richness (std. coefficient $=0.44$ ). Ectomycorrhizal fungal abundance was positively correlated with pine abundance (std. coefficient $=0.80, P<$ 0.001 ), resulting in a negative indirect effect of invasion on ectomycorrhizae (std. coefficient $=-0.30$; Fig. 6c). Saprotrophs were less abundant with greater pine abundance (std. coefficient $=-0.69, P<0.001$ ), creating a 
A

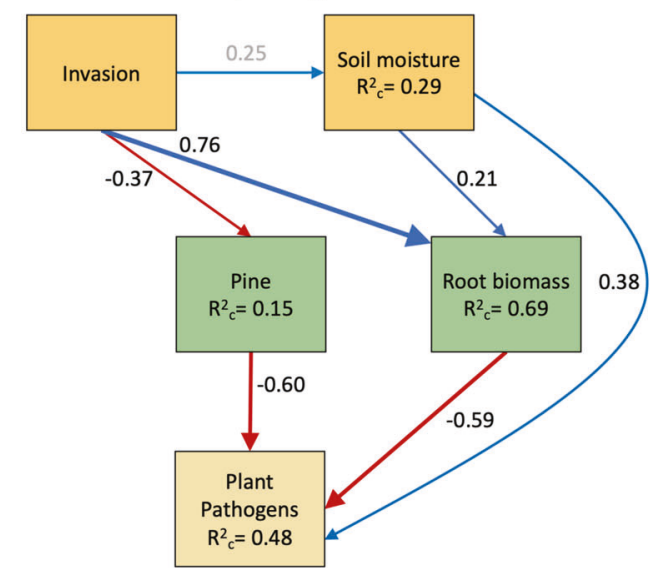

C

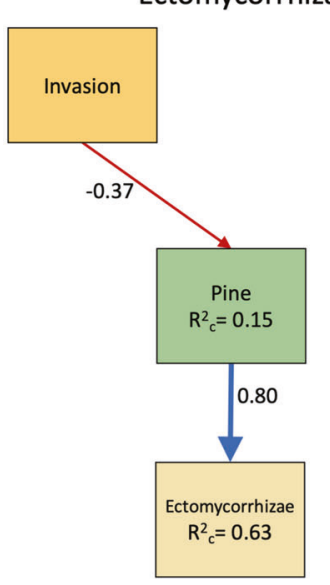

Fig. 6 Path diagrams showing the relationships between invasion and drought treatments, plant communties, and fungal guilds. Relative abundance of (a) plant pathogens, (b) arbuscular mycorrhizae, (c) ectomycorrhizae, (d) saprotrophs where blue arrows indicate positive relationships and red arrows indicate negative relationships. Standardized path coefficients are shown next to the arrows and arrow size is scaled to the strength of the coefficients. Solid arrows and black

positive indirect effect of invasion on saprotroph abundance (std. coefficient $=0.28$; Fig. $6 \mathrm{~d}$ ).

The structural equation models of bacterial functional groups explained $51 \%$ of the variability in relative abundance of FG2-denitrifiers, 20\% of FG3-aerobic chemoheterotrophs, $66 \%$ of FG7-hydrocarbon degraders, and $16 \%$ of FG8-nitrate reducers. We also tested FG4-aerobic nitrite oxidizers but there were no significant paths in the final reduced model. There was a direct negative effect of invasion on FG2 (std. coefficient $=-0.95, P<0.01$ ) and a negative effect of plant richness (std. coefficient $=-0.85$, $P<0.01)$ creating a positive indirect effect of invasion (std. coefficient $=0.74$; Fig. $7 \mathrm{a}$ ). There was also a direct negative effect of invasion on FG3 (std. coefficient $=$ $-0.53, P=0.04$ ) and a positive effect of root biomass (std. coefficient $=0.69, P=0.01$ ), creating indirect positive

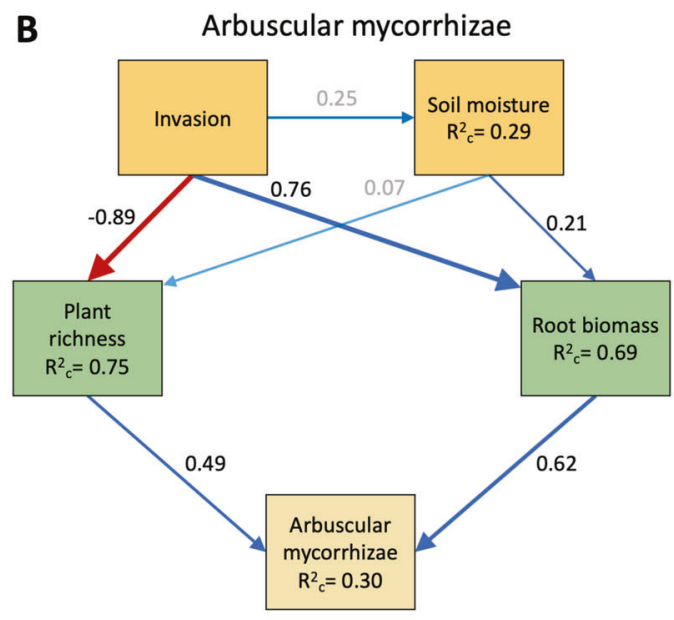

D Saprotrophs

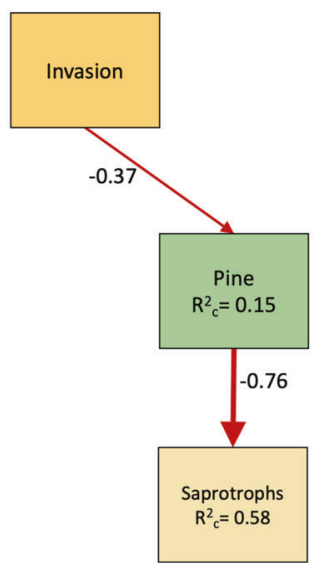

coefficients indicate a significant relationship $(P<0.05)$ while faded arrows and gray coefficients indicate a non-significant relationship $(P>0.05)$ and the level of transparency of the arrows corresponds to the $P$ value. The conditional $R^{2}$ (based on the variance of both the fixed and random effects) for the component mixed effects models are shown in the boxes for the response variables.

effects of invasion and soil moisture (std. coefficient $=$ $0.52,0.15$; Fig. $7 \mathrm{~b}$ ). There was also a direct negative effect of invasion on FG7 (std. coefficient $=-0.27, P=0.03$ ) and a negative effect of pine (std. coefficient $=-0.49, P<$ 0.01 ) creating a positive indirect effect of invasion (std. coefficient $=0.18$; Fig. $7 \mathrm{c}$ ). There was a positive effect of root biomass on FG8 (std. coefficient $=0.40, P=0.01$ ) creating positive indirect effects for both invasion and soil moisture (std. coefficient $=0.30,0.08$; Fig. $7 \mathrm{~d}$ ).

\section{Discussion}

We quantified the individual and interactive effects of plant invasion and drought on the soil microbiome and evaluated the direct versus indirect pathways of these effects through 
Denitrifiers

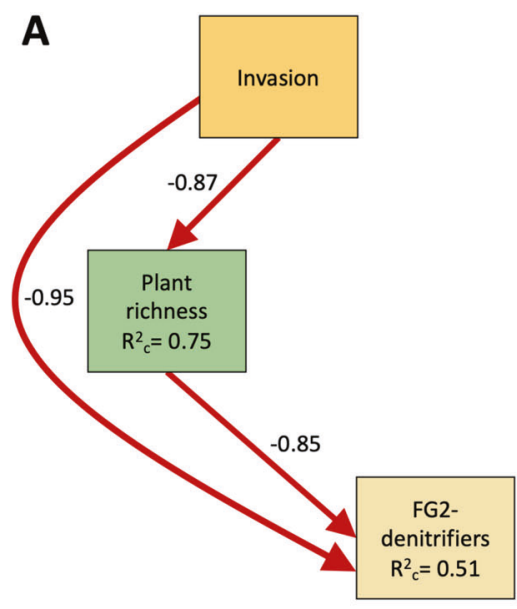

Hydrocarbon degraders

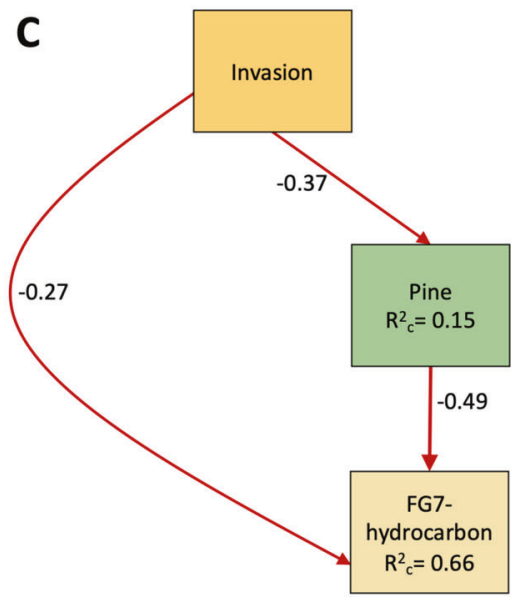

Fig. 7 Path diagrams showing the relationships between invasion and drought treatments, plant communties, and bacterial functional groups. Relative abundance of (a) functional group 2 (includes functions: aerobic chemoheterotrophy, anoxygenic photoautotrophy, chemoheterotrophy, denitrification, nitrate reduction, nitrate respiration, nitrite respiration, photoautotrophy, photoheterotrophy, and phototrophy), (b) functional group 3 (includes functions: aerobic chemoheterotrophy, and chemoheterotrophy), (c) functional group 7 (includes functions: chemoheterotrophy, hydrocarbon degradation, methanotrophy, and methylotrophy), (d) functional group 8 (includes functions:

changes in plant community structure. Our results showed that microbial communities were interactively affected by invasion and drought. Specifically, invasion and drought together had less of an effect on microbial communities than either treatment alone, suggesting alleviation of one treatment by the other. In addition, invasion had strong positive direct effects on both fungal and bacterial richness but also opposing indirect effects through the plant community that moderated overall invasion effects. We demonstrated that the interactive effects of invasion and drought on microbial communities can be nonadditive and that plant communities

\section{Aerobic chemoheterotrophs}

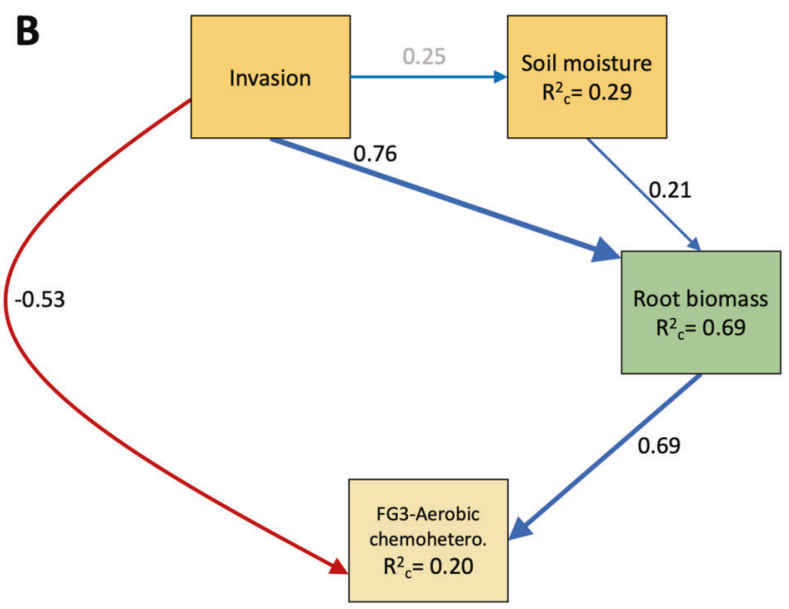

Nitrate reducers

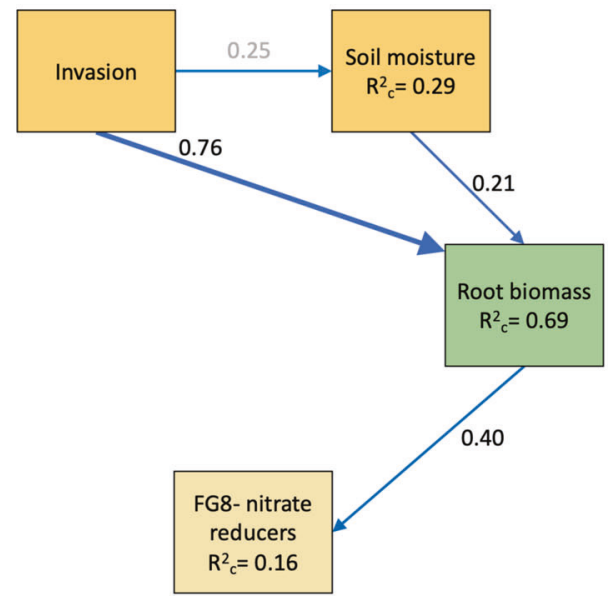

chemoheterotrophy, fermentation, and nitrate reduction). Blue arrows indicate positive relationships and red arrows indicate negative relationships. Standardized path coefficients are shown next to the arrows and arrow size is scaled to the strength of the coefficients. Solid arrows and black coefficients indicate a significant relationship $(P<0.05)$ while faded arrows and gray coefficients indicate a non-significant relationship $(P>0.05)$ and the level of transparency of the arrows corresponds to the $P$ value. The conditional $R^{2}$ (based on the variance of both the fixed and random effects) for the component mixed effects models are shown in the boxes for the response variables.

play a major role in mediating the effects of global change factors on microbial communities.

While instantaneous gravimetric soil moisture was independently affected by invasion and drought, long-term measurements of volumetric soil moisture demonstrated that soil moisture was elevated under invasion in the drought treatment but less so with ambient precipitation [32]. Bacterial richness closely mirrored differences in instantaneous soil moisture across the treatments with lower richness under drought and community composition most altered by drought [23]. Conversely, fungal richness was 
lower under invasion and drought individually but showed complete offsetting of the effect with invasion and drought together, indicating that the interactive effects of invasion and drought on fungal richness were antagonistic [63] (also referred to as mitigating synergism [64]). Similar patterns were observed for fungal community composition, where communities with invasion and drought together were more similar to the uninvaded ambient plots than plots with either treatment alone. These results may indicate that bacteria are more strongly driven by instantaneous soil moisture, while fungi are more sensitive to long-term patterns in soil moisture [65].

Both direct and indirect effects of the treatments on the plant community had major effects on microbial richness. Invasion had a strong positive direct effect but negative indirect effects on both fungal and bacterial richness. Effects of soil moisture followed the same pattern for fungal richness with a positive direct effect and negative indirect effect. As expected, plant richness was positively correlated with both fungal and bacterial richness, suggesting that the complexity of the plant community is a primary driver of microbial richness [9]. Contrary to our hypothesis, pine abundance was negatively correlated with fungal richness suggesting that a dominant native species can homogenize the fungal community [12]. Root biomass was also negatively correlated with fungal richness, perhaps because much of the variation in root biomass was associated with invader roots. This relationship suggests that higher belowground productivity associated with the invader can reduce fungal richness, while the reduction in root biomass with drought can increase fungal richness [12, 15, 66]. Overall, the direct effects of the invasion and drought treatments on microbial richness were balanced by the indirect effects through alterations to the plant community.

Despite the rise in studies assessing microbial responses to environmental conditions, there is still considerable debate about which microbial taxa respond to drought stress [21, 67-69]. In this study, restructuring of fungal communities occurred mainly at lower taxonomic levels. Relative abundance of the order Sebacinales and specifically the family Serendipitaceae was greater in invaded plots, suggesting that they may associate with $I$. cylindrica. These taxa can have complex interactions with plants, as saprotrophs or as plant endophytes and mycorrhizal fungi [70, 71]. Relative abundance of Glomeraceae, which is considered to be the most ruderal AM fungal family, was unaffected by invasion but was lower under drought [5, 21, 72]. AM fungi as a whole were negatively affected by drought through lower root biomass [73]. They were also negatively affected by invasion through plant richness but positively through root biomass, and these indirect effects counteracted each other. Results from previous studies on AM fungal response to invasion have been mixed, with some studies showing either higher or lower AM fungal abundance and diversity, and others showing no response to invasion [17, 39, 74-77]. Some of this variability across studies could be due to the mycorrhizal status of the invader. This hypothesis is supported by the positive effect of I. cylindrica invasion through greater root biomass on AM fungi. However, the negative effect of invasion through lower plant richness indicates that plant interactions can mediate invader impacts on AM fungi.

Ectomycorrhizal abundance was driven by the abundance of pine, which was negatively affected by invasion. Contrary to previous studies suggesting a direct allelopathic effect of I. cylindrica on ectomycorrhizae [38], our results indicated an indirect negative pathway through the abundance and possibly vigor of pine trees. Saprotrophs were also affected by invasion through pine abundance but with a positive indirect effect. This trade-off in relative abundance of saprotrophs and ectomycorrhizae could indicate a switch from saprotroph to ectomycorrhizal dominance in the role as decomposers with pine abundance [78, 79].

Some invasive plants modify the soil microbiome in ways that have negative impacts on native plants, including reductions in beneficial mutualists and accumulation of harmful pathogens [80-83]. Imperata cylindrica invasion had indirect negative effects on fungal plant pathogens through reduction of root biomass and pine abundance. The negative association of plant pathogens with root biomass and pine abundance suggests that I. cylindrica and pine may inhibit pathogens, perhaps because of associations with mycorrhizal fungi [84]. Soil moisture had a positive direct effect on plant pathogens, confirming previous studies showing pathogen susceptibility to desiccation [85, 86]. Differences in the responses of pathogens, mutualists, and saprotrophs to invasion and drought could play a role in plant community dynamics. Future work should test whether changes in abundance of these fungal groups have differential effects on the invader versus native species [87].

In regards to bacterial taxa, some studies suggest that Bacteriodetes and Planctomycetes are susceptible to drought, while Firmicutes, Chloroflexi, and Actinobacteria are more abundant under drought conditions [23]. However, we found that only relatively rare bacterial taxa responded to drought. Most previous studies on the impacts of drought on microbial communities have been conducted in dry systems (e.g., [6, 88-90]). More studies in mesic ecosystems are needed because microbes could show considerably different responses to drought based on acclimation to particular abiotic conditions [91, 92].

We found that bacteria associated with denitrification and other functions (FG2) were more abundant under drought particularly in uninvaded plots. While denitrification is a primarily anaerobic process, denitrifying bacteria are facultative anaerobes and denitrification can occur in 
anaerobic microsites such as within soil aggregates [93]. Bacteria associated with nitrate reduction (FG8) were more abundant under drought and those associated with ureolysis (FG9) were interactively affected by invasion and drought $[23,94]$. While additional work is needed to determine if the genes for these processes are active, previous studies suggest that changes in nitrogen cycling have the potential to create positive feedbacks with invader growth [95]. Furthermore, we found that all of the most abundant bacterial functional groups were influenced by some aspect of the plant community (i.e., plant richness, pine abundance, or root biomass). These results suggest the potential for changes in nitrogen cycling under invasion and drought driven by changes in the soil bacterial communities and mediated by plant communities.

We showed that both abiotic and biotic factors influenced soil microbial community structure. We expected that both invasion and drought would have negative direct effects on the microbial community, but instead we found that invasion had direct positive effects on microbial richness. However, reductions in plant richness associated with invasion created a strong negative indirect effect of invasion on microbial richness. These results indicate that loss of plant diversity with invasion could drive loss of microbial diversity. Contrary to our hypothesis, pine abundance and root biomass were negatively associated with fungal richness, while for bacteria neither were significantly related to richness. Soil moisture was positively associated with fungal but not bacterial richness, and the negative indirect effect of soil moisture through belowground biomass counteracted the positive direct effect. Overall, plant communities proved to be essential mediators of both biotic and abiotic global change factors on the soil microbiome, and by assessing these indirect effects we can begin to tease apart the complexity of the interactive effects of anthropogenic environmental change.

Acknowledgements This project was supported by Natural Sciences and Engineering Research Council of Canada to PMA (RGPIN-201506060); and USDA McIntire-Stennis Project FLA-AGR-005180, Florida Forest Service, Florida Department of Agriculture and Consumer Services Contract\# 21942 to SLF.

\section{Compliance with ethical standards}

Conflict of interest The authors declare that they have no conflict of interest.

Publisher's note Springer Nature remains neutral with regard to jurisdictional claims in published maps and institutional affiliations.

\section{References}

1. Graham EB, Knelman JE, Schindlbacher A, Siciliano S, Breulmann M, Yannarell A, et al. Microbes as engines of ecosystem function: when does community structure enhance predictions of ecosystem processes? Front Microbiol. 2016;7:214.

2. Castro HF, Classen AT, Austin EE, Norby RJ, Schadt CW. Soil microbial community responses to multiple experimental climate change drivers. Appl Environ Microbiol. 2010;76:999-1007.

3. Drigo B, Nielsen UN, Jeffries TC, Curlevski NJA, Singh BK, Duursma RA, et al. Interactive effects of seasonal drought and elevated atmospheric carbon dioxide concentration on prokaryotic rhizosphere communities. Environ Microbiol. 2017;19:3175-85.

4. Carey CJ, Michael Beman J, Eviner VT, Malmstrom CM, Hart SC. Soil microbial community structure is unaltered by plant invasion, vegetation clipping, and nitrogen fertilization in experimental semi-arid grasslands. Front Microbiol. 2015;6:466.

5. Zhang K, Shi Y, Jing X, He JS, Sun R, Yang Y, et al. Effects of short-term warming and altered precipitation on soil microbial communities in alpine grassland of the Tibetan Plateau. Front Microbiol. 2016;7:1032.

6. Pérez Castro S, Cleland EE, Wagner R, Al Sawad R, Lipson DA. Soil microbial responses to drought and exotic plants shift carbon metabolism. ISME J. 2019;13:1776-87.

7. Sheik CS, Beasley WH, Elshahed MS, Zhou X, Luo Y, Krumholz LR. Effect of warming and drought on grassland microbial communities. ISME J. 2011;5:1692-1700.

8. Lange M, Habekost M, Eisenhauer N, Roscher C, Bessler H, Engels $\mathrm{C}$, et al. Biotic and abiotic properties mediating plant diversity effects on soil microbial communities in an experimental grassland. PLoS ONE. 2014;9:e96182.

9. Zak DR, Holmes WE, White DC, Peacock AD, Tilman D. Plant diversity, soil microbial communities, and ecosystem function: Are there any links? Ecology. 2003;84:2042-50.

10. Roy-Bolduc A, Laliberté E, Boudreau S, Hijri M. Strong linkage between plant and soil fungal communities along a successional coastal dune system. FEMS Microbiol Ecol. 2016;92:fiw156.

11. Koyama A, Steinweg JM, Haddix ML, Dukes JS, Wallenstein MD. Soil bacterial community responses to altered precipitation and temperature regimes in an old field grassland are mediated by plants. FEMS Microbiol Ecol. 2018;94:fix156.

12. Bergelson J, Vivanco JM, Manter DK, Broz AK, Broeckling CD. Root exudates regulate soil fungal community composition and diversity. Appl Environ Microbiol. 2007;74:738-44.

13. Eisenhauer N, Lanoue A, Strecker T, Scheu S, Steinauer K, Thakur MP, et al. Root biomass and exudates link plant diversity with soil bacterial and fungal biomass. Sci Rep. 2017;7:44641.

14. Karlowsky S, Augusti A, Ingrisch J, Akanda MKU, Bahn M, Gleixner G. Drought-induced accumulation of root exudates supports post-drought recovery of microbes in mountain grassland. Front Plant Sci. 2018;9:1593.

15. Zhang P, Li B, Wu J, Hu S. Invasive plants differentially affect soil biota through litter and rhizosphere pathways: a meta-analysis. Ecol Lett. 2019;22:200-10.

16. Burns JH, Anacker BL, Strauss SY, Burke DJ. Soil microbial community variation correlates most strongly with plant species identity, followed by soil chemistry, spatial location and plant genus. AoB Plants. 2015;7:plv030.

17. Roberts KJ, Anderson RC. Effect of garlic mustard [Alliaria petiolata (Beib. Cavara \& Grande)] extracts on plants and arbuscular mycorrhizal (AM) fungi. Am Midl Nat. 2001;146:146-52.

18. Broz AK, Manter DK, Vivanco JM. Soil fungal abundance and diversity: another victim of the invasive plant Centaurea maculosa. ISME J. 2007;1:763-5.

19. Burke EJ, Brown SJ, Christidis N. Modeling the recent evolution of global drought and projections for the twenty-first century with the Hadley Centre Climate Model. J Hydrometeorol. 2006;7:1113-25.

20. Singh D, Tsiang M, Rajaratnam B, Diffenbaugh NS. Precipitation extremes over the continental United States in a transient, 
high-resolution, ensemble climate model experiment. J Geophys Res Atmos. 2013;118:7063-86.

21. Ochoa-Hueso R, Collins SL, Delgado-Baquerizo M, Hamonts K, Pockman WT, Sinsabaugh RL, et al. Drought consistently alters the composition of soil fungal and bacterial communities in grasslands from two continents. Glob Chang Biol. 2018;24:2818-27.

22. Manzoni S, Schimel JP, Porporato A. Responses of soil microbial communities to water stress: Results from a meta-analysis. Ecology. 2011;93:930-8.

23. Naylor D, Coleman-Derr D. Drought stress and root-associated bacterial communities. Front Plant Sci. 2018;8:2223.

24. Alba C, NeSmith JE, Fahey C, Angelini C, Flory SL. Methods to test the interactive effects of drought and plant invasion on ecosystem structure and function using complementary common garden and field experiments. Ecol Evol. 2017;7:1442-52.

25. Levine JM, Vilà M, D'Antonio CM, Dukes JS, Grigulis K, Lavorel S. Mechanisms underlying the impacts of exotic plant invasions. Proc R Soc B Biol Sci. 2003;270:775-81.

26. Suseela V, Tharayil N. Decoupling the direct and indirect effects of climate on plant litter decomposition: Accounting for stressinduced modifications in plant chemistry. Glob Chang Biol. 2018;24:1428-51.

27. Yang J, Kloepper JW, Ryu CM. Rhizosphere bacteria help plants tolerate abiotic stress. Trends Plant Sci. 2009;14:1-4.

28. Augé RM. Water relations, drought and vesicular-arbuscular mycorrhizal symbiosis. Mycorrhiza. 2001;11:3-42.

29. Frost C. History and future of the longleaf pine ecosystem. In: Jose S, Jokela EJ, Miller DL, editors. The longleaf pine ecosystem: ecology, silviculture, and restoration. New York, NY: Springer; 2007. p. $9-42$.

30. Estrada JA, Flory SL. Cogongrass (Imperata cylindrica) invasions in the US: mechanisms, impacts, and threats to biodiversity. Glob Ecol Conserv. 2015;3:1-10

31. Brewer S. Declines in plant species richness and endemic plant species in longleaf pine savannas invaded by Imperata cylindrica. Biol Invasions. 2008;10:1257-64.

32. Fahey C, Angelini C, Flory SL. Grass invasion and drought interact to alter the diversity and structure of native plant communities. Ecology. 2018;99:2692-702.

33. Bradley BA, Wilcove DS, Oppenheimer M. Climate change increases risk of plant invasion in the Eastern United States. Biol Invasions. 2010;12:1855-72.

34. Anthony MA, Frey SD, Stinson KA. Fungal community homogenization, shift in dominant trophic guild, and appearance of novel taxa with biotic invasion. Ecosphere. 2017;8:e01951.

35. Nguyen NH, Song Z, Bates ST, Branco S, Tedersoo L, Menke J, et al. FUNGuild: An open annotation tool for parsing fungal community datasets by ecological guild. Fungal Ecol. 2016;20:241-8.

36. Matulich KL, Weihe C, Allison SD, Amend AS, Berlemont R, Goulden ML, et al. Temporal variation overshadows the response of leaf litter microbial communities to simulated global change. ISME J. 2015;9:2477-89.

37. Cline LC, Schilling JS, Menke J, Groenhof E, Kennedy PG. Ecological and functional effects of fungal endophytes on wood decomposition. Funct Ecol. 2018;32:181-91.

38. Hagan DL, Jose S, Lin CH. Allelopathic exudates of cogongrass (Imperata cylindrica): implications for the performance of native pine savanna plant species in the Southeastern US. J Chem Ecol. 2013;39:312-22.

39. Lekberg Y, Gibbons SM, Rosendahl S, Ramsey PW. Severe plant invasions can increase mycorrhizal fungal abundance and diversity. ISME J. 2013;7:1424-33.

40. Melillo JM, Richmond TC, Yohe GW. Highlights of climate change impacts in the United States: the third national climate assessment. Washington DC, USA: Global Change Research Program; 2014.
41. Yahdjian L, Sala OE. A rainout shelter design for intercepting different amounts of rainfall. Oecologia. 2002;133:95-101.

42. Taylor DL, Walters WA, Lennon NJ, Bochicchio J, Krohn A, Caporaso JG, et al. Accurate estimation of fungal diversity and abundance through improved lineage-specific primers optimized for Illumina amplicon sequencing. Appl Environ Microbiol. 2016; 82:7217-26.

43. Bates ST, Berg-Lyons D, Caporaso JG, Walters WA, Knight R, Fierer N. Examining the global distribution of dominant archaeal populations in soil. ISME J. 2011;5:908-17.

44. Gao C, Montoya L, Xu L, Madera M, Hollingsworth J, Purdom E, et al. Strong succession in arbuscular mycorrhizal fungal communities. ISME J. 2018;13:214-26.

45. Caporaso JG, Bittinger K, Bushman FD, Desantis TZ, Andersen GL, Knight R. PyNAST: a flexible tool for aligning sequences to a template alignment. Bioinformatics. 2010;26:266-7.

46. McDonald D, Price MN, Goodrich J, Nawrocki EP, Desantis TZ, Probst A, et al. An improved Greengenes taxonomy with explicit ranks for ecological and evolutionary analyses of bacteria and archaea. ISME J. 2012;6:610-8.

47. Edgar RC. Search and clustering orders of magnitude faster than BLAST. Bioinformatics. 2010;26:2460-1.

48. Stackebrandt E, Goebel BM. Taxonomic note: a place for DNADNA reassociation and $16 \mathrm{~S}$ rRNA sequence analysis in the present species definition in bacteriology. Int $\mathrm{J}$ Syst Bacteriol. 1994;44:846-9.

49. Bengtsson-Palme J, Ryberg M, Hartmann M, Branco S, Wang Z, Godhe A, et al. Improved software detection and extraction of ITS1 and ITS2 from ribosomal ITS sequences of fungi and other eukaryotes for analysis of environmental sequencing data. Methods Ecol Evol. 2013;4:914-9.

50. Altschul SF, Gish W, Miller W, Myers EW, Lipman DJ. Basic local alignment search tool. J Mol Biol. 1990;215:403-10.

51. Kõljalg U, Nilsson RH, Abarenkov K, Tedersoo L, Taylor AFS, Bahram M, et al. Towards a unified paradigm for sequence-based identification of fungi. Mol Ecol. 2013;22:5271-7.

52. Koyama A, Maherali H, Antunes PM. Plant geographic origin and phylogeny as potential drivers of community structure in rootinhabiting fungi. J Ecol. 2019;107:1720-36.

53. Price MN, Dehal PS, Arkin AP. Fasttree: computing large minimum evolution trees with profiles instead of a distance matrix. Mol Biol Evol. 2009;26:1641-50.

54. Louca S, Parfrey LW, Doebeli M. Decoupling function and taxonomy in the global ocean microbiome. Science. 2016;353:1272-7.

55. R Development Core Team. R: a language and environment for statistical computing. R Foundation for Statistical Computing, Vienna, Austria 2016; 3.3.1. https://www.r-project.org/.

56. Pinheiro J, Bates D, DebRoy S, Sarkar D, The R Development Core Team. nlme: linear and nonlinear mixed effects models. $\mathrm{R}$ Package version 31-113. 2016. R package: 1-86.

57. Chao A. Nonparametric estimation of the numbers of classes in a population. Scand J Stat. 1984;11:265-70.

58. Oksanen J, Blanchet FG, Kindt R, Legendre P, Minchin PR, O'Hara RB, et al. vegan: community ecology package. R Packag version 24-1. 2016.

59. Anderson MJ, Walsh DCI. PERMANOVA, ANOSIM, and the mantel test in the face of heterogeneous dispersions: what null hypothesis are you testing? Ecol Monogr. 2013;83:557-74.

60. Mandal S, Van Treuren W, White RA, Eggesbø M, Knight R, Peddada SD. Analysis of composition of microbiomes: a novel method for studying microbial composition. Micro Ecol Health Dis. 2015;26:27663.

61. Lefcheck JS. piecewiseSEM: Piecewise structural equation modelling in R for ecology, evolution, and systematics. Methods Ecol Evol. 2016;7:573-9. 
62. Alba C, Fahey C, Flory SL. Global change stressors alter resources and shift plant interactions from facilitation to competition over time. Ecology. 2019;100:e02859.

63. Folt CL, Chen CY, Moore MV, Burnaford J. Synergism and antagonism among multiple stressors. Limnol Oceanogr. 1999;44:864-77.

64. Piggott JJ, Townsend CR, Matthaei CD. Reconceptualizing synergism and antagonism among multiple stressors. Ecol Evol. 2015;5:1538-47.

65. Hawkes CV, Kivlin SN, Rocca JD, Huguet V, Thomsen MA, Suttle KB. Fungal community responses to precipitation. Glob Chang Biol. 2011;17:1637-45.

66. Horner-Devine MC, Leibold MA, Smith VH, Bohannan BJM. Bacterial diversity patterns along a gradient of primary productivity. Ecol Lett. 2003;6:613-22.

67. Evans SE, Wallenstein MD, Burke IC. Is bacterial moisture niche a good predictor of shifts in community composition under longterm drought. Ecology. 2014;95:110-22.

68. Maestre FT, Delgado-Baquerizo M, Jeffries TC, Eldridge DJ, Ochoa V, Gozalo B, et al. Increasing aridity reduces soil microbial diversity and abundance in global drylands. Proc Natl Acad Sci USA. 2015;112:15684-9.

69. Zhou Z, Wang C, Luo Y. Response of soil microbial communities to altered precipitation: a global synthesis. Glob Ecol Biogeogr. 2018;27:1121-36.

70. Weiß M, Sýkorová Z, Garnica S, Riess K, Martos F, Krause C, et al. Sebacinales everywhere: previously overlooked ubiquitous fungal endophytes. PLoS ONE. 2011;6:e16793.

71. Weiß M, Waller F, Zuccaro A, Selosse M-A. Sebacinales-one thousand and one interactions with land plants. N Phytol. 2016; 211:20-40.

72. Chagnon P-L, Bradley RL, Maherali H, Klironomos JN. A traitbased framework to understand life history of mycorrhizal fungi. Trends Plant Sci. 2013;18:484-91.

73. Staddon PL, Thompson K, Jakobsen I, Grime JP, Askew AP, Fitter AH. Mycorrhizal fungal abundance is affected by long-term climatic manipulations in the field. Glob Chang Biol. 2003;9:186-94.

74. Mummey DL, Rillig MC. The invasive plant species Centaurea maculosa alters arbuscular mycorrhizal fungal communities in the field. Plant Soil. 2006;288:81-90.

75. Hawkes CV, Belnap J, D'Antonio C, Firestone MK. Arbuscular mycorrhizal assemblages in native plant roots change in the presence of invasive exotic grasses. Plant Soil. 2006;281:369-80.

76. Vogelsang KM, Bever JD. Mycorrhizal densities decline in association with normative plants and contribute to plant invasion. Ecology. 2009;90:399-407.

77. Cipollini D, Cipollini K. A review of garlic mustard (Alliaria petiolata, Brassicaceae) as an allelopathic plant. J Torre Bot Soc. 2016;143:339-48.

78. Talbot JM, Allison SD, Treseder KK. Decomposers in disguise: mycorrhizal fungi as regulators of soil $\mathrm{C}$ dynamics in ecosystems under global change. Funct Ecol. 2008;22:955-63.
79. Lindahl BD, Tunlid A. Ectomycorrhizal fungi-potential organic matter decomposers, yet not saprotrophs. N Phytol. 2015;205:1443-7.

80. Eppinga MB, Rietkerk M, Dekker SC, De Ruiter PC, Van Der Putten WH. Accumulation of local pathogens: a new hypothesis to explain exotic plant invasions. Oikos. 2006;114:168-76.

81. Stinson KA, Campbell SA, Powell JR, Wolfe BE, Callaway RM, Thelen GC, et al. Invasive plant suppresses the growth of native tree seedlings by disrupting belowground mutualisms. PLoS Biol. 2006;4:727-31.

82. Barto EK, Antunes PM, Stinson K, Koch AM, Klironomos JN, Cipollini D. Differences in arbuscular mycorrhizal fungal communities associated with sugar maple seedlings in and outside of invaded garlic mustard forest patches. Biol Invasions. 2011;13:2755-62.

83. Batten KM, Scow KM, Espeland EK. Soil microbial community associated with an invasive grass differentially impacts native plant performance. Micro Ecol. 2008;55:220-8.

84. Whipps JM. Prospects and limitations for mycorrhizas in biocontrol of root pathogens. Can J Bot. 2004;82:1198-227.

85. Cook RJ, Papendick RI. Influence of water potential of soils and plants on root disease. Annu Rev Phytopathol. 1972;10:349-74.

86. Krupa SV, Dommergues YR. Ecology of root pathogens. Amsterdam, The Netherlands: Elsevier Scientific Pub. Co.; 1979.

87. Reynolds HL, Packer A, Bever JD, Clay K. Grassroots ecology: plant-microbe-soil interactions as drivers of plant community structure and dynamics. Ecology. 2003;84:2281-91.

88. Armstrong A, Valverde A, Ramond JB, Makhalanyane TP, Jansson JK, Hopkins DW, et al. Temporal dynamics of hot desert microbial communities reveal structural and functional responses to water input. Sci Rep. 2016;6:34434.

89. Bachar A, Al-Ashhab A, Soares MIM, Sklarz MY, Angel R, Ungar ED, et al. Soil microbial abundance and diversity along a low precipitation gradient. Micro Ecol. 2010;69:453-61.

90. Clark JS, Campbell JH, Grizzle H, Acosta-Martìnez V, Zak JC. Soil microbial community response to drought and precipitation variability in the chihuahuan desert. Micro Ecol. 2009;57:248-60.

91. Fierer N, Schimel JP, Holden PA. Influence of drying-rewetting frequency on soil bacterial community structure. Micro Ecol. 2003;45:63-71.

92. Evans SE, Wallenstein MD. Soil microbial community response to drying and rewetting stress: does historical precipitation regime matter? Biogeochemistry. 2012;109:101-16.

93. Seitzinger S, Harrison JA, Böhlke JK, Bouwman AF, Lowrance R, Peterson B, et al. Denitrification across landscapes and waterscapes: a synthesis. Ecol Appl. 2006;16:2064-90.

94. Hawkes CV, Wren IF, Herman DJ, Firestone MK. Plant invasion alters nitrogen cycling by modifying the soil nitrifying community. Ecol Lett. 2005;8:976-85.

95. Lee MR, Flory SL, Phillips RP. Positive feedbacks to growth of an invasive grass through alteration of nitrogen cycling. Oecologia. 2012;170:457-65. 